\title{
Application of the $h p$-finite element method to modeling thermal fields of high voltage underground cables buried in multi-layer soil
}

- Vu Phan Tu

VNU-HCM

- Vo Van Hoang Long

Lilama 2 College, DongNai

(Manuscript Received on September $30^{\text {th }}, 2013$, Manuscript Revised October $28^{\text {th }}, 2013$ )

\begin{abstract}
:
In this paper, we investigate the application of the adaptive higher-order Finite Element Method (hp-FEM) to heat transfer problems in electrical engineering. The proposed method is developed based on the combination of the Delaunay mesh and higher-order interpolation functions. In which the Delaunay algorithm based on the distance function is used for creating the adaptive mesh in the whole solution domain and the higher-order polynomials (up to $9^{\text {th }}$ temperature distribution.

\section{INTRODUCTION}

The underground cables system, which is one of main transmission and distribution systems of power systems, is used by the power companies and industry in densely populated cities instead of overhead lines even its installation and maintenance are more expensive and complicated. Moreover, the stability and safety operations of buried power cables are the expectation of power utilities.
\end{abstract}

order) are applied for increasing the accuracy of solution. To evaluate the applicability and effectiveness of this new approach, we applied the proposed method to solve a benchmark heat problem and to calculate the temperature distribution of some typical models of buried double- and single -circuit power cables in the homogenous and multi-layer soils, respectively.

Keywords: Underground cables, Adaptive higher-order finite element method (hp-FEM),

The important characteristics in operation and design of the underground power cables are the current-carrying capacity and usable working life. These values very much depend on the maximum operating temperature and the ability to transfer the cables-generated heat to the surrounding soil domain. Therefore, the thermal field computation of buried power cables is a very important task of many power engineers, researchers and manufactures all over the world.

\section{Trang 72}


In general, this problem is solved by using the analytical and/or numerical methods. In particular, the results of developments and applications of the numerical methods to engineering problems have gained much attention in recent years.

The numerical methods, such as Finite Difference Nethod (FDM, Boundary El enent Method (BEM) and Fi ni te El enent Method (FEM and Meshfree nethods, with their advantage is to provide more accurate simulating than the analytical method in complex geometries have been appling to calculate several practical heat transfer problems in el ectrical engi neering such as the thernal field di stri buti on of underground cabl es [1][4], heat si nul ation for MEMS design [5] and thermal field of transforner [6]. In recent years, the $h p$ - FEM has been strongly developed [7]-[8] and successfully applied to many problems of civil, mechanical and electrical engineering [9] due to this method has given the very high accurate solutions. Besides, the adaptive Delaunay mesh that is still used in the application to FE - [10] creates the flexible FE mesh in the whole solving region. Which means that the small-size elements are much more efficient and distributed in domain where the solution has important features. Thus this algorithm can decrease CPU times but still ensure the high accuracy of numerical solution.

Unfortunately, the application of the $h p$-FEM to heat transfer problems is very rare. For this reason, we have proposed an approach of the $h p$ FEM that is the combination of the adaptive Delaunay mesh and higher-order interpolation functions. The advantages of this approach are that it strongly increases the accuracy of solution and can decrease the CPU times compared with the uniform mesh and/or lower-order FEM. In order to demonstrate the advantage and applicability of this method, we have used it to test on the benchmark heat problem and to calculate the steady-state thermal distribution of some typical power cable systems buried in the homogenous and multi-layer soils.

\section{THE $h p$-FEM FOR THERMAL TRANSFER PROBLEMS}

In general, the Poisson equation describes the steady state heat transfer in homogeneous medium can be written as

$$
\nabla .(k \nabla T)+Q=0
$$

where $k\left({ }^{\circ} \mathrm{Cm} / \mathrm{W}\right)$ is the thermal resistivity of medium. $Q(\mathrm{~W} / \mathrm{m})$ is the heat generation rate in the heat source and $T\left({ }^{\circ} \mathrm{C}\right)$ is the unknown temperature.

In the two-dimensional medium, the unknown temperature function $T^{e}(x, y)$ in (1) can be approximated in per element by terms of the $p^{\text {th }}$ order polynomial as follows

$$
\begin{aligned}
& T^{e}(x, y)=\sum_{i=1}^{n} a_{i}^{e} q_{i}(x, y)=a^{T} q(x, y) \\
& \text { where } n=(2) \\
& (p+1)(p+2) / 2 \text { is the total number }
\end{aligned}
$$
of nodes in per element and $q(x, y)=\left[1, x, y, x^{2}, x y, y^{2}, \ldots, y^{p}\right]$.

The unknown coefficients of $a_{i}^{e}$ in (2) can be determined by enforcing (2) at $n$ nodes and then they are substituted back into (2). Thus (2) can be written as follows

$$
T^{e}(x, y)=\sum^{n} \Phi_{i}^{e}(x, y) T_{i}^{e}
$$

where $\Phi_{i}^{e}$ is the interpolation function is given by

$\Phi_{i}^{e}=P_{I}^{n}\left(L_{1}^{e}\right) P_{J}^{n}\left(L_{2}^{e}\right) P_{K}^{n}\left(L_{3}^{e}\right), \quad I+J+K=n$

In which [7] we have

$P_{\alpha}^{n}\left(L_{1}^{e}\right)=\prod_{m=0}^{\alpha-1} \frac{p L_{1}^{e}-m}{\alpha-m}=\frac{1}{\alpha !} \prod_{m=0}^{\alpha-1}\left(p L_{1}^{e}-m\right)$ with $\alpha=I, J, K>0$

with $L_{1}^{e}, L_{2}^{e}, L_{3}^{e}$ are the area coordinates of $e^{\text {th }}$ element.

In the $h p$-FE procedure, the whole solving domain is subdivided by the triangular elements, where the total number of nodes in per element depends on the order of interpolation polynomial. 
The $h p$-FE solution will be obtained by minimizing the numerical integrations of piecewise polynomials. Finally, we have the matrix equation as follows

$$
\mathbf{A} \mathbf{T}=\mathbf{b}
$$

where $\mathbf{T}$ is a column vector of temperatures at finite element nodes, $\mathbf{A}$ is the heat conductivity matrix with

$$
A_{i j}^{e}=\iint_{\Omega^{e}}\left(k_{x} \frac{\partial \Phi_{i}^{e}}{\partial x} \frac{\partial \Phi_{j}^{e}}{\partial x}+k_{y} \frac{\partial \Phi_{i}^{e}}{\partial y} \frac{\partial \Phi_{j}^{e}}{\partial y}\right) d x d y \quad i, j=1,2, \ldots, n
$$

and $\mathbf{b}$ is a vector is given by

$$
b_{i}^{e}=\iint Q \Phi_{i}^{e} d x d y \quad i=1,2, \ldots, n
$$

\section{NUMERICAL RESULTS}

\section{Benchmark heat problem}

In order to demonstrate the advantage of the the hp-FEM, we now apply it to the benchmark heat problem which has the following equation

$$
k \nabla^{2} T(x, y)+Q=0, \quad x, y \in \Omega=[0,1]^{2}
$$

where one assumes that $k=1$ and without internal heat source - [5], and the function values on boundaries are as

$$
\begin{array}{cc}
T(x, y)=0 & x, y \in \Gamma_{1}, \\
\frac{\partial T(x, y)}{\partial x}=0 & x, y \in \Gamma_{2}, \\
T(x, y)=\sin (\pi x) & x, y \in \Gamma_{3}, \\
-\frac{\partial T(x, y)}{\partial x}=0 & x, y \in \Gamma_{4},
\end{array}
$$

Table I. Error of HP-FE Solutions Of Benchmark Problem

\begin{tabular}{|c|c|c|c|}
\hline Methods & Number of nodes & Number of elements & $L_{\infty}$ \\
\hline $1^{\text {st }}$-order FEM & 400 & 722 & $2.1465 \mathrm{e}-004$ \\
\hline $2^{\text {nd }}-$ order FEM & 1521 & 722 & $1.3601 \mathrm{e}-007$ \\
\hline $3^{\text {rd }}-$ order FEM & 3364 & 722 & $2.6232 \mathrm{e}-008$ \\
\hline $4^{\text {th }}-$ order FEM & 5929 & 722 & $8.8536 \mathrm{e}-012$ \\
\hline $5^{\text {th }}-$ order FEM & 9216 & 722 & $3.9838 \mathrm{e}-013$ \\
\hline $6^{\text {th }}-$ order FEM & 13225 & 722 & $3.4861 \mathrm{e}-014$ \\
\hline
\end{tabular}

Where

$\Gamma_{1}=\{(x, y): 0 \leq x \leq 1, y=0\} \Gamma_{2}=\{(x, y): 0 \leq y \leq 1, x=1\}$,

$\Gamma_{3}=\{(x, y): 0 \leq x \leq 1, y=1\}, \Gamma_{4}=\{(x, y): 0 \leq y \leq 1, x=0\}$

The analytical solution of this benchmark problem is given by

$$
T(x, y)=\frac{2}{\pi} y-\frac{4}{\pi} \sum_{n=1}^{\infty} \frac{\cos (2 n \pi x) \sinh (2 n \pi y)}{\left(4 n^{2}-1\right) \sinh (2 n \pi)}
$$

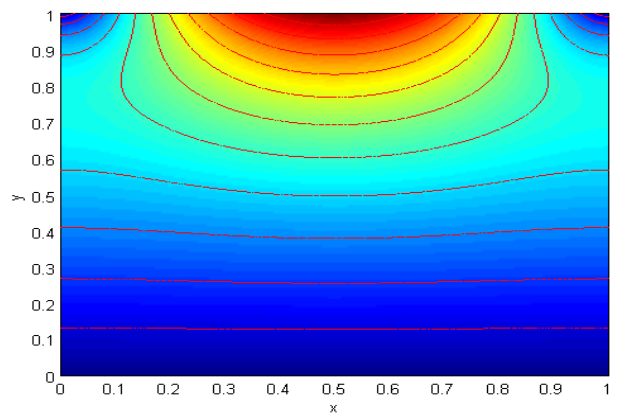

Fig. 1. Contour plot of benchmark problem.

In this section, we have used the higher-order (up to $6^{\text {th }}$-order) FEM to solve this benchmark problem. The contour plot of isothermal lines and the error comparison between the higher-order FE solutions are illustrated in Fig.1. and TABLE.I., respectively. It has shown that the solutions of the higher-order FEM are much more accurate than the one of the $1^{\text {st }}$-order FEM.

\section{Trang 74}


Temperature distribution of three-phase cable system buried in homogenous soil

In this section, we present the application of the $h p$-FEM to calculate the temperature distribution of high voltage underground cables buried in rectangular homogenous soil as in
Fig.2. Besides, the following assumptions are also given as

The effect of radiation and convection at the ground surface are neglected, Thermal resistivity of soil is constant, The length of cable is more larger than its buried depth.

Table II. Parameters specification - [1]

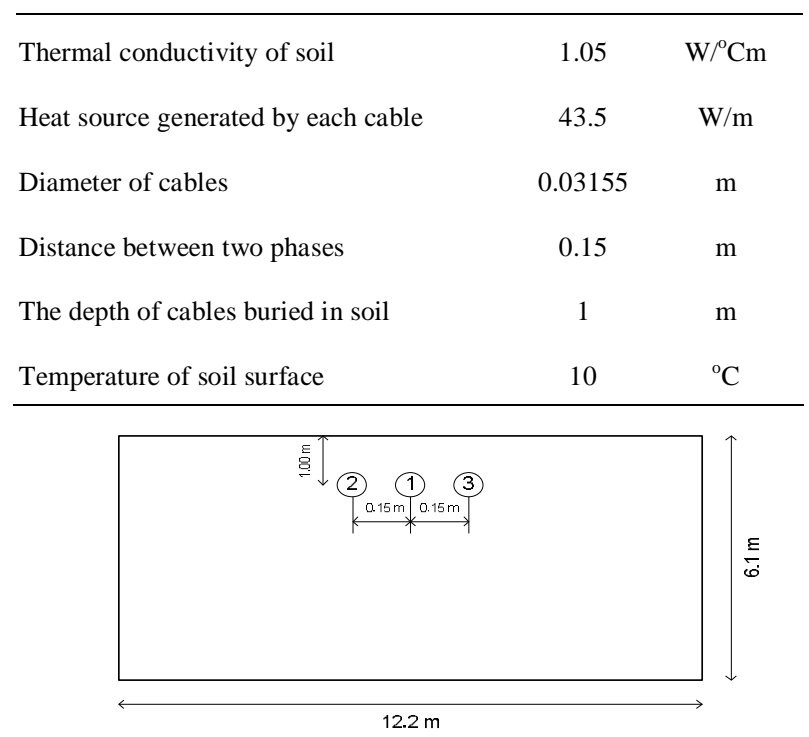

Fig. 2. Model of the buried three-phase cable system in rectangular soil.

As above introduced, the first step of the adaptive $h p$-FE procedure is to subdivide the solving domain by mean of adaptive triangular elements corresponding to nodes. In this work, we use the adaptive Delaunay algorithm [10] to create the adaptive elements in the whole solving domain, and then we apply the higher-order interpolation polynomial to each element.
Finally, the $h p$-FE solutions are obtained by solving (6). In this approach, each conductor of cable system is assumed to be a heat source and data of this problem given by TABLE.II. The results are illustrated in Figs. 3.-.7. The comparison between the $h p$-FE solutions and those of FDM, BEM and COMSOL software is presented in TABLE.III.

Table III. Comparison of Numerical Solutions of Cable Temperatures

\begin{tabular}{|c|c|c|c|c|c|}
\hline \multirow{2}{*}{ Methods } & \multirow{2}{*}{ Nodes } & \multirow{2}{*}{ Elements } & \multicolumn{3}{|c|}{ Average Temperature $\left({ }^{\circ} \mathrm{C}\right)$} \\
\cline { 4 - 6 } & & & Cable 2 & Cable 1 & Cable 3 \\
\hline $1^{\text {st }}$-order FEM & 259 & 465 & 68.0953 & 72.7356 & 68.1626 \\
\hline $2^{\text {nd }}$ - order FEM & 985 & 465 & 70.7892 & 75.4573 & 70.7851 \\
\hline $3^{\text {rd }}$ - order FEM & 2176 & 465 & 70.8615 & 75.5333 & 70.8616 \\
\hline
\end{tabular}




\begin{tabular}{|c|c|c|c|c|c|}
\hline $4^{\text {th }}-$ order FEM & 3832 & 465 & 70.8775 & 75.5491 & 70.8776 \\
\hline $5^{\text {th }}-$ order FEM & 5953 & 465 & 70.8780 & 75.5499 & 70.8781 \\
\hline $6^{\text {th }}-$ order FEM & 8539 & 465 & 70.8810 & 75.5528 & 70.8810 \\
\hline $7^{\text {th }}-$ order FEM & 11590 & 465 & 70.8809 & 75.5528 & 70.8810 \\
\hline $8^{\text {th }}-$ order FEM & 15106 & 465 & 70.8814 & 75.5534 & 70.8815 \\
\hline $9^{\text {th }}-$ order FEM & 19087 & 465 & 70.8812 & 75.5532 & 70.8813 \\
\hline COMSOL & 1683 & 3237 & 70.7690 & 75.4940 & 70.9480 \\
\hline FDM & - & - & 68.7690 & 72.3170 & 68.7690 \\
\hline BEM $-[1]$ & - & - & 67.0400 & 71.5500 & 67.0400 \\
\hline
\end{tabular}

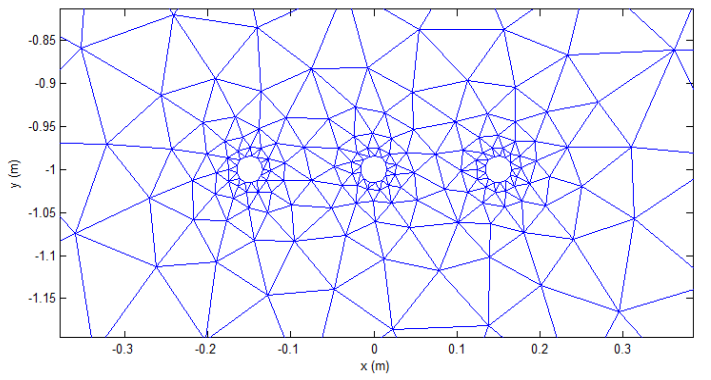

Fig. 3. Zoom solving domain surrounding cables is discretised by using the adaptive $1^{\text {st }}$-order elements.

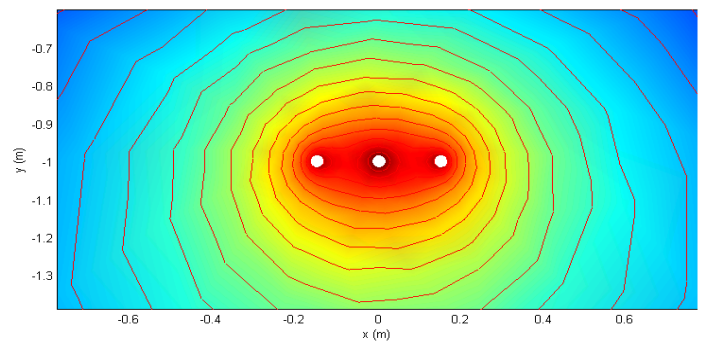

Fig. 4. Contour plot of isothermal lines surrounding cables is solved by the adaptive $1^{\text {st }}$-oder FEM.

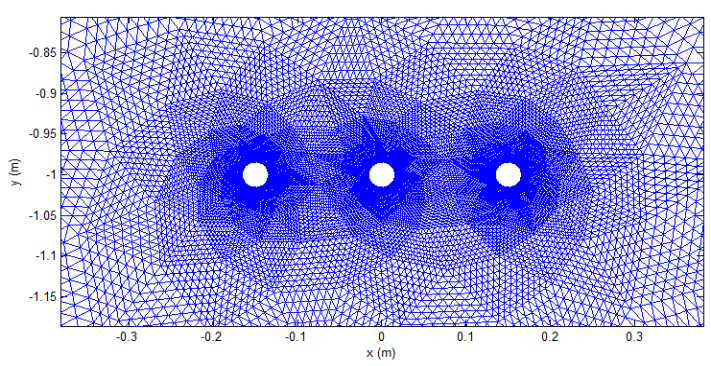

Fig. 5. Zoom solving domain surrounding cables is discretised by using the adaptive $9^{\text {th }}$-order elements.

\section{Trang 76}




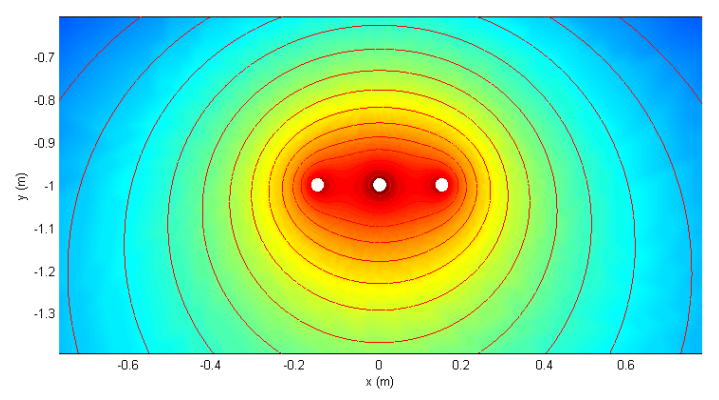

Fig. 6. Contour plot of isothermal lines surrounding cables obtained by using the adaptive $9^{\text {th }}$-oder FEM.

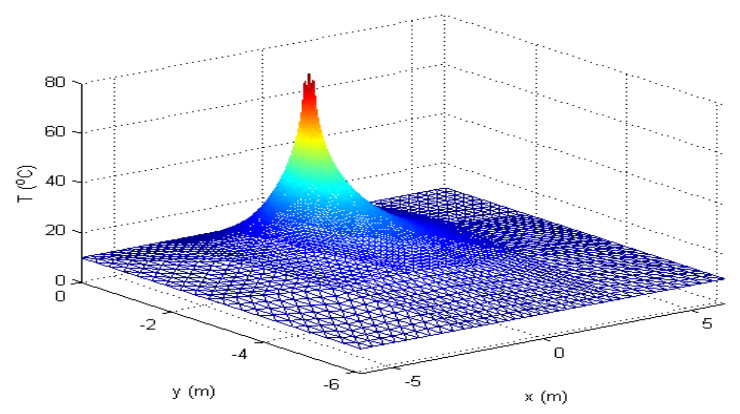

Fig. 6. Temperature of underground cable system is obtained by using the adaptive $9^{\text {th }}$-oder FEM.

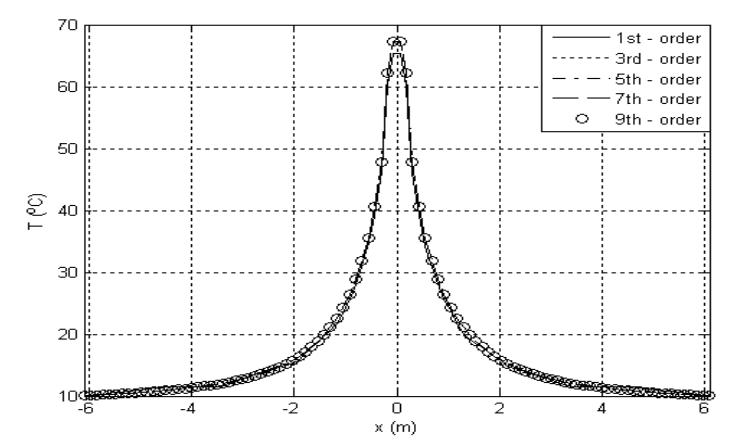

Fig. 7. Comparison of temperature solutions of underground cable system are solved by the adaptive $h p$-FEM.

Temperature distribution of three-phase cable system buried in two-layer soil

In this case, we study the thermal behavior of cables in two-layer medium. We use the cables in the case of double circuit and cables are directly buried at the depth of $1.9 \mathrm{~m}$ in native soil. The boundary beetwen two layer at the depth of $3.0 \mathrm{~m}$.
The values of thermal conductivity of upper and under layer are $1.00\left(\mathrm{~W} /{ }^{\circ} \mathrm{Cm}\right), 1.30\left(\mathrm{~W} /{ }^{\circ} \mathrm{Cm}\right)$, respectively. The ground surface is represented by convective boundary (Cauchy condition) with convection loss coefficient of $5\left(\mathrm{~W} /{ }^{\circ} \mathrm{Cm}^{2}\right)$. The phase spacing of each cable circuit is $0.25 \mathrm{~m}$ and cables still loaded 662A and generate heat rate of $32.029(\mathrm{~W} / \mathrm{m})$. 


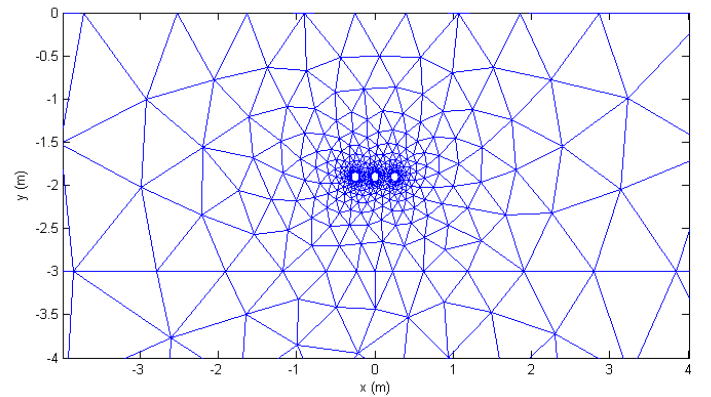

Fig. 8. Domain surrounding cables buried in two-layer soil is discretised by using the adaptive $1^{\text {st }}$-order elements.

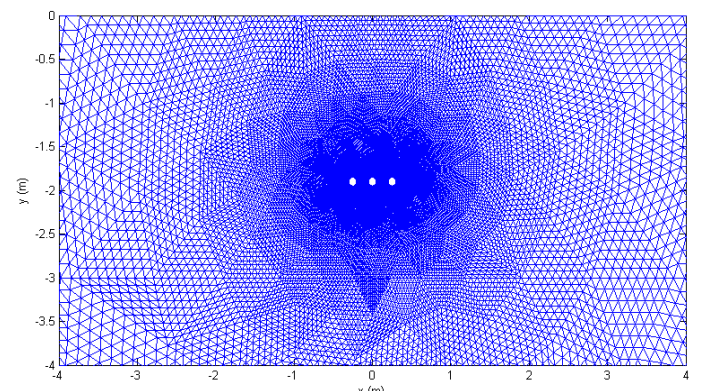

Fig. 9. Domain surrounding cables buried in two-layer soil is discretised by using the adaptive $9^{\text {th }}$-order elements.

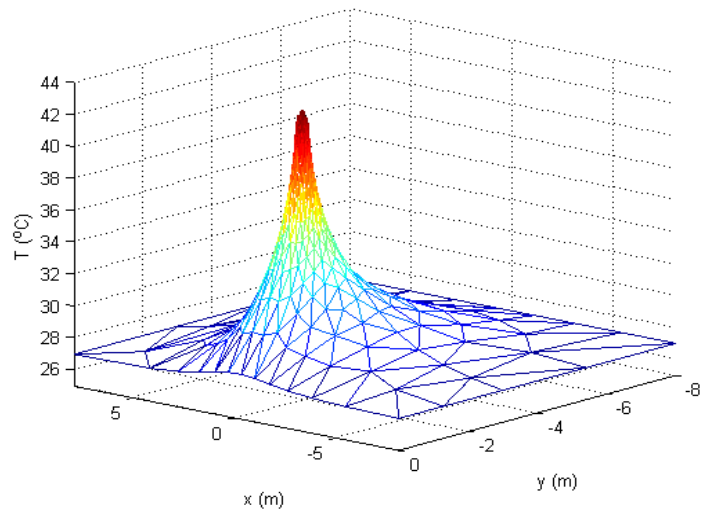

Fig. 10. Temperature of underground cable system buried in two-layer soil is obtained by using the adaptive $1^{\text {st }}$ oder FEM. 


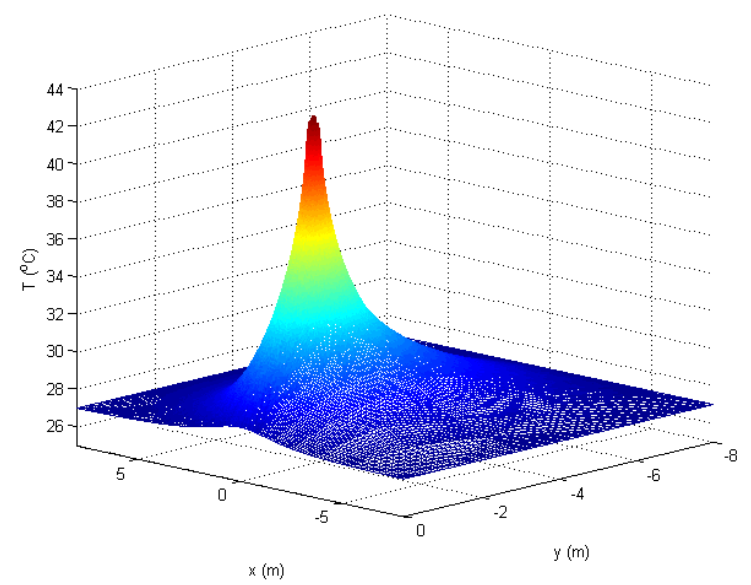

Fig. 11. Temperature of underground cable system buried in two-layer soil is obtained by using the adaptive $9^{\text {th }}$ oder FEM.

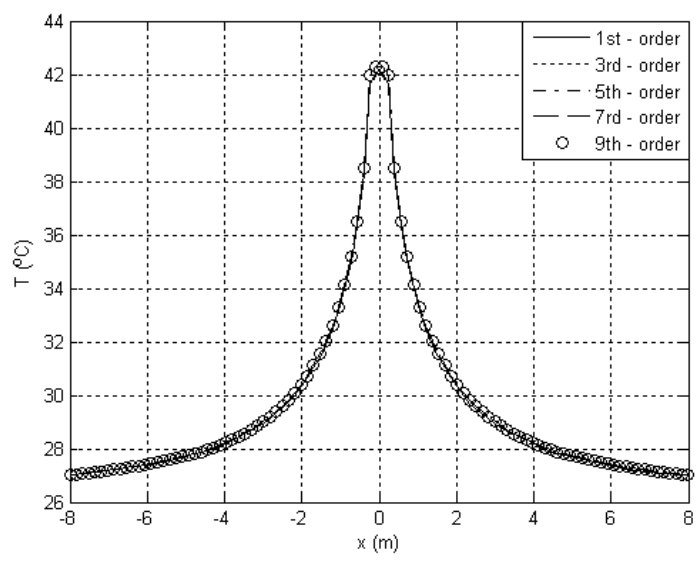

Fig. 12. Comparison of temperature solutions of underground cable system buried in two-layer soil are solved by the adaptive $h p$-FEM.

Temperature distribution of double-circuit three-phase cable system buried in multi-layer soil

In this case, we test the double-circuit threephase underground cables system buried at the depth of $1.9 \mathrm{~m}$ in cable bedding in multi-layer soil. The upper layer is trench backfill and surrounding medium is native soil. The values of thermal conductivity of cable bedding, trench backfill and native soil are $1.00\left(\mathrm{~W} /{ }^{\circ} \mathrm{Cm}\right), 1.25$
$\left(\mathrm{W} /{ }^{\circ} \mathrm{Cm}\right)$ and $0.80\left(\mathrm{~W} /{ }^{\circ} \mathrm{Cm}\right)$, respectively. The width and height of cable bedding are $1.80 \mathrm{~m}$ and $0.6 \mathrm{~m}$, respectively. The ground surface represented by convective boundary (Cauchy condition) with convection loss coefficient of 5 $\left(\mathrm{W} /{ }^{\circ} \mathrm{Cm}^{2}\right)$. The phase spacing of each cable circuit is $0.25(\mathrm{~m})$ and the nearest distance between two circuits is $0.35(\mathrm{~m})$. Cables still loaded $662 \mathrm{~A}$ and generated heat rate of 32.029 $(\mathrm{W} / \mathrm{m})$. The results are illustrated in Figs. 14.-.16. and TABLE IV. 
Table IV. Comparison between HP-FE Solutions of Buried Power cables in Multi-Layer Soil

\begin{tabular}{|c|c|c|c|c|c|c|c|c|}
\hline \multirow{2}{*}{ Order } & \multicolumn{2}{|c|}{ Number of } & \multicolumn{5}{|c|}{ Average Temperature $\left({ }^{\circ} \mathrm{C}\right)$} \\
\cline { 2 - 9 } & Nodes & Elements & Cable 1 & Cable 2 & Cable 3 & Cable 4 & Cable 5 & Cable 6 \\
\hline $1^{\text {st }}$ & 654 & 1190 & 50.3528 & 52.8046 & 53.4084 & 53.4137 & 52.8085 & 50.3554 \\
\hline $2^{\text {td }}$ & 2503 & 1190 & 50.8008 & 53.2756 & 53.8869 & 53.8875 & 53.2762 & 50.8013 \\
\hline $3^{\text {rd }}$ & 5542 & 1190 & 50.8052 & 53.2803 & 53.8917 & 53.8919 & 53.2805 & 50.8054 \\
\hline $4^{\text {th }}$ & 9771 & 1190 & 50.8080 & 53.2832 & 53.8946 & 53.8947 & 53.2835 & 50.8083 \\
\hline $5^{\text {th }}$ & 15190 & 1190 & 50.8078 & 53.2830 & 53.8944 & 53.8946 & 53.2832 & 50.8080 \\
\hline $6^{\text {th }}$ & 21779 & 1190 & 50.8083 & 53.2836 & 53.8950 & 53.8951 & 53.2838 & 50.8085 \\
\hline $7^{\text {th }}$ & 29598 & 1190 & 50.8258 & 53.3010 & 53.9132 & 53.9118 & 53.2998 & 50.8245 \\
\hline $8^{\text {th }}$ & 38587 & 1190 & 50.8127 & 53.2879 & 53.8994 & 53.8993 & 53.2878 & 50.8126 \\
\hline $9^{\text {th }}$ & 48766 & 1190 & 50.8098 & 53.2851 & 53.8966 & 53.8967 & 53.2852 & 50.8098 \\
\hline
\end{tabular}

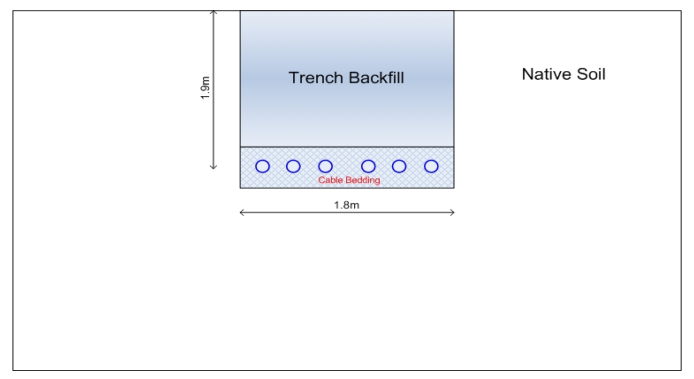

Fig. 13. Double-circuit three-phase cables model in multi-layer soil.

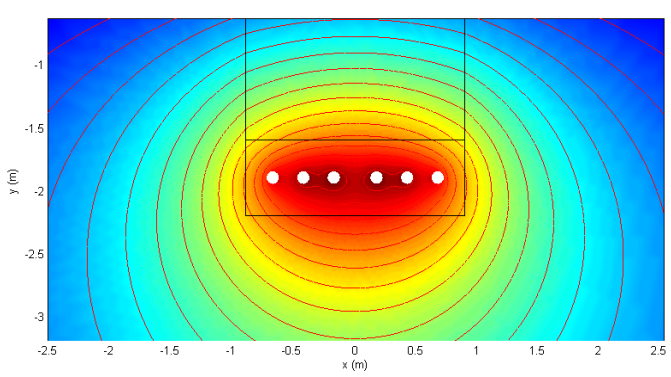

Fig. 14. Contour plot of isothermal lines surrounding double-circuit cable system solved by the $9^{\text {th }}$-oder FEM. 


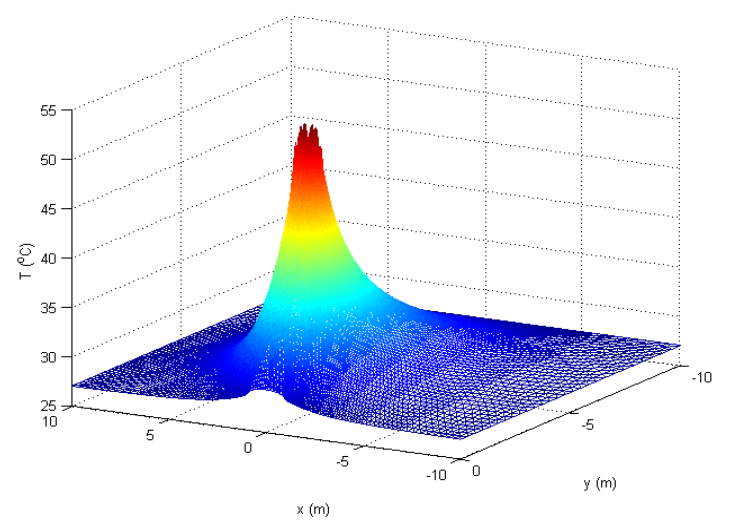

Fig. 15. Temperature of double-circuit cable system solved by the $9^{\text {th }}$-oder FEM.

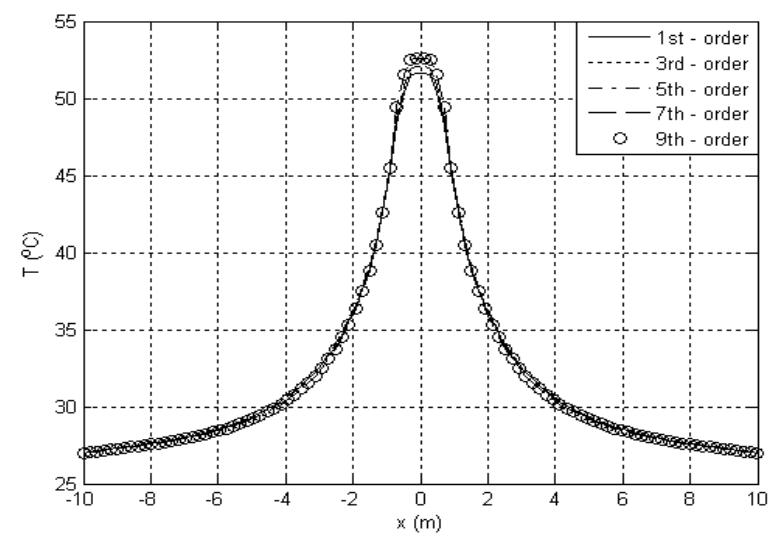

Fig. 16. Comparison of temperature solutions of double-circuit cable system buried in multi-layer soil solved by the $h p$-FEM.

\section{REMARK}

In three tested cases of $A, B, C$ and $D$ of Section .III., we have firstly created the adaptive triangular mesh in the whole solving domain, we have then applied the higher-order interpolation and shape functions (up to $9^{\text {th }}$ order) [7]-[8] to each triangular element. Thus the total numbers of triangles were 722 in case A, 465 of case B, 866 of case $C$ and 1190 of case $D$ corresponding to the total numbers of nodes have increased from 400 to 13225 in case A, from 259 to 19087 in case $B$, from 474 to 35458 in case $C$, and from 654 to 48766 in case $D$. The calculated results have been presented in many Figures and
TABLES. They can give some remarks as follows

TABLE.I. of the benchmark problem has been shown that the $h p$-FE solutions are in good agreement with the analytical one. Thus the proposed method is very strong and efficient for solving the engineering problems defined by the Poisson equation, including the heat transfer and electromagnetic problems, etc.

Due to the mutual effect of adjacent conductors, the temperature of the mid conductor of any cable system is always highest. Besides, due to the characteristic of adaptive mesh, the total number of nodes on per circle modeled 
conductor is equal but their distributed location compared between circles is different, we can see the maximum temperatures of conductor 2 and 3 of case $B$ are different while those of FDM and BEM are equal (see TABLE. .III.). This also appears in case $D$ (see TABLE.IV.).

The $h p$-FEM is successfully applied to the buried cables in multi-layer soil with the convective boundary. It shows the high applicability and effectiveness of the proposed method in complex engineering problems.

The temperature results obtained by the adaptive $h p$-FEM are more accurate than those of BEM, FDM and COMSOL. Thus they are the very good datum for design and operation of underground power cables.

\section{CONCLUSION}

This paper has applied for the first time the $h p$-FEM to calculating the benchmark heat problem and the temperature distribution of underground cable systems in homogeneous and multi-layer soils. The results of the proposed method are compared to those of other methods, it has been seen that the $h p$-FE solutions are much more accurate and the $h p$-FEM is efficiently applied to complex geometrical problems.

\section{Áp dụng phương pháp phần tử hữu hạn bậc cao thích nghi cho mô phỏng trường nhiệt của cáp ngầm cao thế trong đất nhiều lớp}

- Vũ Phan Tú

ĐHQG-HCM

- Võ Văn Hoàng Long

Trường cao đẳng nghề Lilama 2, Đồng Nai

\section{TÓM TÁT:}

Trong bài báo này, chúng tôi nghiên cứu việc áp dụng phương pháp Phần tử hữu hạn bậc cao thích nghi cho các bài toán truyền nhiệt trong ngành kỹ thuật điện. Phương pháp đề nghị được phát triển dựa trên một sự kết hợp giữa lưới Delaunay và hàm nội suy bậc cao. Trong đó, thuật toán Delaunay đặc cơ sở trên hàm khỏang cách được sử dụng cho việc tạo nên lưới thích nghi trong tòan bộ miền lời giải và các đa thức bậc cao

(đến bậc 9) được áp dụng cho việc làm tăng độ chính xác của lời giải. Nhằm đánh giá khả năng áp dụng và hiệu quả của tiếp cận mới này, chúng tôi đã áp dụng phương pháp đề xuất cho việc giải bài toán nhiệt chuẩn và tính tóan phân bố nhiệt độ của một số mô hình đặc trưng của cáp điện lực một mạch và hai mạch được chôn trong đất đồng nhất và nhiều lớp. 


\section{REFERENCES}

[1]. G. Gela, J. J. Dai, "Calculation of Thermal Fields of Underground Cables Using the Boundary Element Method," IEEE Transactions on Power Delivery, Vol. 3, No. 4, pp. 1341-1347, October 1988.

[2]. M. A. Hanna, M. M. A. Salama, "Thermal Analysis of Power Cables in Multi-layered Soil," IEEE Transactions on Power Delivery, Vol. 8, No. 3, pp. 761-771, July 1993.

[3]. Chang-Chou Hwang and Yi-Hsuan Jiang, "Extensions to Finite Element Method for Thermal Analysis of Underground Cables System," Electric Power System Research 64, pp. 159-164, 2003.

[4]. Vũ Phan Tú, Nguyễn Ngọc Khoa, Nguyễn Nhật Nam, "Calculation of Temperature and Ampacity of Underground Cables Using Adaptive Finite Element Methods," Journal of Technology and Science, Vietnam, Vol. 19, No.73B, pp. 39-45, 2009.

[5]. Jean-Baptiste Munier et all, "Investigation of The Meshfree RPIM Solution for a Haptic Sensing Approach to MEMS
Design," 2009 World Congress on Computer and Information Engineering, pp. 97-100., 2009.

[6]. Marina A. Tsili et al, " Hybrid NumericalAnalytical Technique for Power Transformer Thermal Modeling," IEEE Trans. on Magn., Vol. 45,No.3, pp. 14081411, March 2009.

[7]. D. A. Dunavant, "High degree efficient symmetrical Gaussian quadrature rules for the triangle," International Journal of Numerical Methods in Engineering, Vol. 21, No. 6, pp.1129-1148, 1985.

[8]. Pavel Solin, Segeth, K, Ivo Dolezel, Higher-Order Finite Element Method, Chapman\&Hall/CRC -2003.

[9]. S. McFee. D. Ma, "Practical h-p adaptive Finite-Element Analysis Strategies for Irregular Triangles and Tetrahedra," IEEE Trans. on Magn., Vol. 40, pp. 985-988, 2004.

[10]. Paul-Louis George, Houman borouchaki, Delaunay Triangulation and Meshing, Application to Finite Element, HERMES Paris, 1998. 